\title{
Pharmaceutical Promotion Tools Effect on Physicians' Adoption of Medicine Prescribing: Evidence from Jordan
}

\author{
Muhammad Alshurideh ${ }^{1,2}$, Barween Al Kurdi ${ }^{3}$, Ala’ Abdullah Abumari ${ }^{4}$ \& Said A. Salloum ${ }^{5,6}$ \\ ${ }^{1}$ Marketing Department, The University of Jordan, Amman, Jordan \\ ${ }^{2}$ Business Administration, College of Business Administration, Fujairah- UAE \\ ${ }^{3}$ Marketing Department, Amman Arab University, Amman, Jordan \\ ${ }^{4}$ Postgraduate College, The University of Jordan, Amman, Jordan \\ ${ }^{5}$ Faculty of Engineering and IT, The British University in Dubai, Dubai, UAE \\ ${ }^{6}$ Faculty of Engineering and IT, University of Fujairah, Fujairah, UAE \\ Correspondence: Muhammad Alshurideh, Marketing Department, The University of Jordan, Amman, Jordan. Tel: \\ 1-613-947-3592. E-mail: davidwolf@gc.ca
}

Received: May 10, 2018 Accepted: September 20, 2018 Online Published: October 29, 2018

doi:10.5539/mas.v12n11p210

URL: https://doi.org/10.5539/mas.v12n11p210

\begin{abstract}
The study aims to investigate the effect of pharmaceutical promotion tools on physicians' adoption of medicine prescribing in Jordan. Medical representative detailing visits, promotional medicine prices, external medical conference sponsorships, and free sampling were the main promotional tools investigated in this study. The researcher collected primary data using a questionnaire from a judgment sample of 150 practising physicians in the private sector (non-probability sampling) who responded to the study questionnaire. Multiple regression analysis was used to analyze the data. The results indicated that there was a high level of acceptance and effect for the previously mentioned promotional tools on physicians' adoption. The most influential independent variable was promotional medicine price, followed by free sampling, while external medical conference sponsorships and medical representative detailing visits were the lowest influential medical promotional tools. Managers and decision makers who are working in pharmaceutical companies in Jordan were recommended to focus on scientific detailing and free sampling, and to decrease the budget allocated for sponsorship of external medical conferences.
\end{abstract}

Keywords: pharmaceutical promotion, medical representative, medicine price, conference sponsorship, free sampling, adoption

\section{Introduction}

Marketing is a restless, changing, and dynamic business activity. The role of marketing itself has changed dramatically owing to various crises, material and energy shortages, inflation, economic recessions, high rates of unemployment, dying industries, dying companies, terrorism and war, and effects due to rapid technological changes in certain industries. Such changes, including the Internet, have forced today's marketing executives to become more market driven in their strategic decision making, requiring a formalized means of acquiring accurate and timely information about customers, products, the marketplace, and the overall environment. The means to help them do this is marketing research (Smith \& Albaum, 2010). Moreover, marketing is currently considered as an expanding field, and it becomes increasingly important as one of the most important activities and duties of the managerial functions of any organization. Organizations seek to satisfy their business goals; accordingly, they should understand and analyze customers' needs and wants to satisfy them more effectively than their competitors do (Alshurideh et al., 2012; Alshurideh, 2014; Al-Dweeri et al., 2017). Marketers usually apply the marketing activities that are included in the classification of the four Ps of the marketing mix, namely product, price, place, and promotion. Promotion now becomes essential for all industries (Al-Dmour \& Al-Shraideh, 2008), such as the pharmaceutical industry, in which promotion includes all the activities that are directed to increase the products' sales, such as sales promotion, advertising, personal selling, public relations, and direct marketing (McCarthy, 1964). 
Pharmaceutical companies expend vast amounts of money in the research and development (R and $\mathrm{D})$ process to produce a new medicine, which aims to treat patients with certain illnesses, or to improve the existing treatment for certain diseases; while other companies are waiting until the originator company's patency expires, and then start producing a 'copy, which is called generic medicine. Both the originator and the generic medicines are usually bioequivalent. Bioequivalence is defined by American Food and Drug Association (FDA) to be "...the absence of a significant difference in the rate and extent to which the active ingredient or active moiety in pharmaceutical equivalents or pharmaceutical alternatives becomes available at the site of drug action when administered at the same molar dose under similar conditions in an appropriately designed study." (US FDA, 2003). Generic medicines are always available at a lower price, because there is no research and development cost, facilitating the process of penetrating the existing market in order to gain a significant market share from the originator companies. As a result, those pharmaceutical industries produce large quantities of medicines that are distributed among pharmacies. The decision maker who chooses the proper medicine for the patient is not the patient himself who takes the medicine and ends up paying the price; the decision maker is the physician who chooses among an array of medicinal alternatives. Therefore, this study defines the customer in this study as a 'medicine prescriber' who is the physician. A physician is defined as a person who is trained and licensed to practise medicine (American Heritage Dictionary of the English Language, 2011).

The intermediary role they play is an important and significant one. There is a proliferation of $t$ of examples in the literature where the chooser is not the user. Organizational buying, toy purchasing, and textbook buying provide additional examples of situational purchase determinants where the decision maker is not necessarily the user (Kotler, 2000; Alshurideh et al., 2015, 2016; Alshurideh et al., 2012, 2016; Al Kurdi, 2017; Alshurideh, 2017). The revenue gained from patients' purchase of these medicines covers the cost and generates profits for the pharmaceutical companies. Supporters of pharmaceutical promotions claim that marketing expenditures give innovative pharmaceutical manufacturers a fair chance to recover high research and development expenditures. Moreover, marketing may serve as a communication channel to educate physicians and expose consumers to information and medical options that may improve their health outcomes (Kremer, Bijmolt, Leeflang \& Wieringa, 2008).

Many studies had been carried out to investigate the influence of pharmaceutical promotion tools on the prescribing behavior (adoption) of physicians. However, the results were not always consistent(Bhatt, 1993; Pavan, 2008). On the other hand, pharmaceutical marketers in Jordan complained of the scarcity of available studies which investigate the prescribing behavior in the Jordanian medical market. Accordingly, this study aims to answer the following questions: To what extent are pharmaceutical promotional tools accepted by the physicians in Jordan? Secondly, to what extent do pharmaceutical promotional tools affect physicians' medicine adoption (perhaps 'prescribing'?) decisions in Jordan? Thirdly, to what extent are the factors related to the patient able to change the effect of pharmaceutical promotional tools on physicians' prescribing medicines in Jordan? Finally, do these factors maximize or minimize their effect?

The main goal of this paper is to investigate the effect of pharmaceutical promotion tools on physicians' adoption of medicine prescribing in Jordan. In order to achieve that, the following objectives have been fulfilled: To develop a theoretical framework that outlines the hypotheses relationship between the pharmaceutical promotion tools and physicians' adoption of medicine prescribing in Jordan based on the research results and the previous related studies; to investigate the extent of acceptance of physicians in Jordan of the pharmaceutical promotion tools; to assess the effect of pharmaceutical promotion tools on physicians' adoption of medicine prescribing in Jordan; to identify the most influential pharmaceutical promotional tools on physicians' adoption of medicine prescribing in Jordan; and to provide the Jordanian pharmaceutical companies' decision makers with recommendations that might help the marketing units in these companies to increase their focus on physicians. This paper gives an idea about the type and magnitude of the competition between the pharmaceutical companies working in the Jordan market. This study also provides a clear perspective on whether Jordanian patients' needs and preferences affect pharmaceutical promotion.

\section{Literature Review}

This section defines pharmaceutical promotion and explains the tools of promotion which were investigated in this study. Secondly, this study describes the promotional tools which pharmaceutical companies use and their relationship with physicians in Jordan. In order to answer the question "What is pharmaceutical promotion?", this study relied on the American definition of pharmaceutical marketing. According to the Prescription Drug Marketing Act, a law of the United States federal government, “...pharmaceutical marketing is the business of advertising or otherwise promoting the sale of pharmaceuticals or drugs" (U.S. Department of Health and 
Human Services, 2006). The cost of medicine in the USA accounts for $10.7 \%$ of the total cost of health care; for example, in 2004 the USA expenditure on prescribed medicine was \$188.5 billion which is five times more than that in 1990. As a result, the number of medical representatives in the USA increased from 38000 to 100000 between 1995 and 2005 (Menlo \& Henry, 2006).

The goal of pharmaceutical promotion according to Smith (1991) is pharmaceutical care. Pharmaceutical care is the responsible provision of drug therapy for the purpose of achieving the elimination or reduction of a patient's symptomatology, arresting or slowing of a disease process, or preventing a disease or symptomatology (Helper \& Strand, 1989). This involves providing solutions for diseases and sickness in order to improve overall health as well as the public's knowledge of health (Sheehan, 2007). Another aim of pharmaceutical promotion is to gain the biggest market share, which then increases the sales and profits of the manufacturer or the wholesaler (Rubin, 2004). As mentioned before, supporters of pharmaceutical promotion always claim that this profit is needed to cover the research and development expenditure. In addition, pharmaceutical promotion may be used as a communication channel to educate physicians and expose them to information that may improve the health outcomes and medical options of their patients (Rubin, 2003).

Pharmaceutical companies promote their medicines using many tools; one of these is the medical representative detailing visit during which the promotion of medicine for the physicians takes place for use in their clinic where they practice medicine. The ratio is one medical representative for every 2.5 physicians in the USA, but it is noted that not all physicians are currently practising and not all practising physicians are covered by pharmaceutical promotion because medical representatives only visit high prescribers (Fugh-Berman \& Ahari, 2007). Companies always select medical representatives who are more dynamic, have excellent communication skills, and who are well trained to be helpful, observant and personable. Companies also train medical representatives on how to assess preferences, personalities and lifestyles of physicians: sometimes personal information is more valuable than prescribing related information. Therefore, medical representatives ask for details about physicians' family life, professional interests, and recreational sports. A photograph on a physician's desktop gives a representative an opportunity to gain information about family members and memorize whatever information is offered (including names, birthdays, and interests). Usually this information is saved in a company's records (Fugh-Berman \& Ahari, 2007). More than \$4.8 billion was spent on one-to-one promotion of medicines to physicians by medical representatives, and this is one of the main factors which increased the average of sales expenditure for pharmaceutical companies ( $\$ 875$ million annually) (Fugh-Berman \& Ahari, 2007). Millenson (2003) indicated that physicians relied on the information provided by medical representatives and considered them a convenient source. Medical representative information was the main source for more than half of the high-prescriber physicians.

Since the price of medicine also plays a major role in the prescribing process, pricing is considered as one of the most important decisions for any company. Price affects medicines' buyer needs directly, and it determines the profit that the company would gain after the deduction of the total costs ( $\mathrm{R}$ and $\mathrm{D}$ cost, marketing cost, sales cost, among others). Thus, all the company departmental reports are usually consulted by top management to determine a suitable price for the product (Yang, Lien \& Chou, 2014). The prices of patent medicines are usually considered high (due to the absence of the generic competitors, according to the patency laws), and therefore, the patients are not able to obtain these medicines except as the originator patent product. Accordingly, the company with a valid patent will not reduce its prices. The patency period enables many pharmaceutical companies to recoup the costs that they have expended during the development stage of the product (research and development expenditure). On average, $\$ 500$ million of $\mathrm{R}$ and $\mathrm{D}$ outlays are needed before one successful new medicine can be marketed (DiMasi, Hansen, \& Grabowski, 2003). Once a patency period has expired, generic competitors appear with lower prices which enables these companies to achieve a profitable margin. Generic competitors with the same medicine types have different, but generally comparable prices (this is the same for the Jordanian market).

Many studies have indicated that high medicine prices and patient co-payments are important factors which influence physicians' prescription choice behavior (Gönül, Carter, Petrova \& Srinivasan, 2001; Miao-Sheng \& Yu-Ti, 2008; Nutescu et al., 2005). In the Netherlands, the government offers very low financial incentives for general practitioners (GPs) or specialists to prescribe cheap medicines if they are available as an alternative. However, since the physicians are the decision makers and are targeted by most of the pharmaceutical companies, huge promotional activities lead to higher prices in a market (Windmeijer, De Laat, Douven \& Mot, 2004). 
Based on the above discussion and previous literature, this study endeavors to fill the gap in literature by evaluating the effect of pharmaceutical promotion tools on physicians' adoption of medicine prescribing in Jordan owing to a lack of studies in developing counties, especially in Jordan.

\section{The Study Model and Hypotheses}

The proposed theoretical research model has been developed based on a literature review and explores the research objectives as seen above. Figure 1 displays the proposed relationship between the variables of the study.

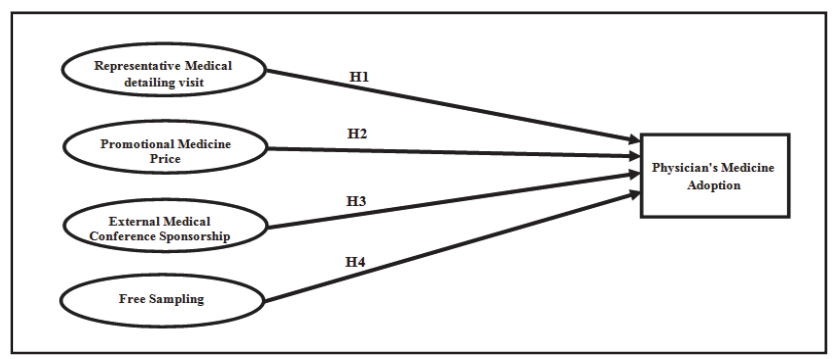

Figure 1. Research model

\section{Research Hypothesis}

The hypothesis is H1: The pharmaceutical promotion tools (medical representative detailing visit, promotional medicine price, external medical conference sponsorship and free sampling) have a positive effect on physicians' adoption of the promoted medicine. This research is considered as an exploratory, quantitative, cross-sectional research where a scale adopted from previous studies is used to measure the relationship between independent and dependent variables: every variable is measured according to a set of questions which were used previously by other studies.

\section{Methodology}

Typical descriptive research is involved with the measurement of conditions, procedures, attitudes, opinions and demographic information. This study chose a survey research as the study design. The survey is considered as a trial to collect data from a sample of population (physicians) in order to scientifically determine their status regarding a group of variables and the relationships between these variables. The survey research at its best can provide very valuable data. It involves a careful design and execution of each of the components of the research process. This study designed a survey tool that was administrated to the research sample. The purpose of the survey instrument was to collect data about the attitudes and opinions toward the pharmaceutical promotion tool's effect on physicians' adoption of medicine prescribing in Jordan.

The population of this research was the physicians in Jordan who work in private clinics and hospitals. These amount to 6192 registered physicians (Jordan Department of Statistics, Statistical Yearbook, 2009). Physicians who work in the public sector have been excluded from this research because the public sector is generally not a target for pharmaceutical promotion because it depends on tender purchasing; accordingly, it uses all the medicine which has been ordered without any need for promotion. The chosen sample of this study is a judgment sample that includes different genders, educational levels, age categories, number of patients seen per day, experience level, practising location, and area of specialization. Sample members were selected based on their experience and knowledge about topics which are discussed in the research and their willingness to participate freely and answer the research questions without any financial incentives or other interfering issues such as social considerations. The judgment sample is considered as part of the non-probability sampling design; this study relies on the researcher's experience to find respondents who have suitable characteristics required in the sample (Zikmund, 2003).

The questionnaire was distributed by the researcher who ensured that it was correctly filled in by the targeted doctors. Distributing and collecting the questionnaire for this research was very difficult and time consuming due to the following reasons: Many physicians, even in those in the private sector, have not been exposed to the pharmaceutical promotion tools which this study is investigating, so they were excluded. Many Physicians are very busy or have limited time at their clinics and hospitals, therefore the researcher could not reach them. Some physicians refused to answer the questionnaire because they found it too long and time consuming. Other 
physicians refused to answer some or all of the questions owing to social considerations, so their responses were excluded from the study. Some questionnaires were excluded because physicians had left some questions unanswered. A total of 500 questionnaires were distributed to physicians 200 physicians from different levels participated, 150 questionnaires were returned, and 50 questionnaires were excluded from the analysis because of incomplete information. Therefore, there were 150 questionnaires that were valid for analysis. Table 1 shows the demographic characteristics of the study sample.

Table 1. Demographic characteristics of the sample

\begin{tabular}{|c|c|c|}
\hline & \multicolumn{2}{|c|}{ Sample } \\
\hline & Frequency & Ratio \% \\
\hline \multicolumn{3}{|l|}{ Gender } \\
\hline Male & 124 & 82.7 \\
\hline Female & 26 & 17.3 \\
\hline Total & 150 & 100.0 \\
\hline \multicolumn{3}{|l|}{ Age } \\
\hline 30 and below & 7 & 4.7 \\
\hline More than $30-40$ years & 25 & 16.7 \\
\hline More than $40-50$ years & 94 & 62.7 \\
\hline More than $50-60$ years & 20 & 13.3 \\
\hline More than 60 years & 4 & 2.7 \\
\hline Total & 150 & 100.0 \\
\hline \multicolumn{3}{|l|}{ Qualification } \\
\hline General Practitioner & 75 & 50.0 \\
\hline Resident physician & 10 & 7.3 \\
\hline Specialist & 31 & 20.3 \\
\hline Consultant & 34 & 22.4 \\
\hline Total & 150 & 100.0 \\
\hline \multicolumn{3}{|l|}{ Work Experience } \\
\hline 5 years and below & 7 & 4.7 \\
\hline More than 5- 10 years & 20 & 13.3 \\
\hline More than $10-15$ years & 101 & 67.3 \\
\hline More than $15-20$ years & 12 & 8.0 \\
\hline More than $20-25$ years & 7 & 4.7 \\
\hline More than 25 years & 3 & 2.0 \\
\hline Total & 150 & 100.0 \\
\hline \multicolumn{3}{|c|}{ Quantity of Patients seen per day } \\
\hline 15 and below & 78 & 52.0 \\
\hline $16-30$ patients & 40 & 26.7 \\
\hline $31-45$ patients & 20 & 13.3 \\
\hline 45 and more & 12 & 8.0 \\
\hline Total & 150 & 100.0 \\
\hline \multicolumn{3}{|l|}{ Practicing Type } \\
\hline Private Clinic & 84 & 56.0 \\
\hline Private Hospital & 46 & 30.7 \\
\hline Both of them & 20 & 13.3 \\
\hline Total & 150 & 100.0 \\
\hline \multicolumn{3}{|l|}{ Practicing Area } \\
\hline Amman & 87 & 58.0 \\
\hline
\end{tabular}




\begin{tabular}{lcc}
\hline Zarqa & 26 & 17.3 \\
Southern Area & 15 & 10.0 \\
Irbid & 22 & 14.7 \\
Total & 150 & 100.0 \\
Specialization & & \\
General Practitioner & 75 & 50 \\
General Surgeon & 17 & 11.3 \\
Pediatric & 16 & 10.7 \\
Emergency & 15 & 10 \\
Dermatology & 9 & 6 \\
Gynecologist & 18 & 12 \\
Total & 150 & 100.0 \\
\hline
\end{tabular}

The adopted questionnaire employs a five-point scale; it contains 23 questions and respondents were asked to answer those questions by ranking their answers from one to five, in which five represents 'strongly agree' and one represents 'strongly disagree'. The questionnaire was distributed by the researcher himself and was completed by physicians who represent the research sample.

A quantitative approach entails a systematic standardized approach and employs various methods such as surveys. This study relied on data collection by means of the questionnaire, and the study sample responses. This questionnaire consisted of two sections, namely: Section One: Demographic variables; and Section Two: Statements of the study tool. The demographic information was collected by means of closed-ended questions, comprising seven (7) factors, namely gender, age, qualification, work experience, number of patients, and place of professional practice. Statements of the study tool contained information relating to representative medical detailing visits (five statements), promotional medicine price (five statements), external medical conference sponsorship (four statements), free sampling (four Statements) and physician's medicine adoption (five Statements).

\subsection{Validity and Reliability}

To test the questionnaire for clarity and to provide a coherent research questionnaire, a macro review that covered all the research constructs was accurately performed by academic reviewers from the Jordan University and other university experts in the Administration, Marketing, and Pharmacy sections. The questionnaire was submitted to ten (10) reviewers, nine (9) of which were faculty members in the University of Jordan in addition to one (1) reviewer from another University (Nottingham University). They were requested to verify the authenticity of the content, and to give their opinions, to re-word some questions, to make the required modifications, and to carefully check the balance in the content and weighting of the questions. To calculate the stability of an instrument study, this study used the equation of internal consistency using Cronbach's alpha and test results where the values of Cronbach alpha for all variables of the study and identification of generally higher than $(60 \%)$ which is acceptable in the research and studies, which gives the questionnaire as a whole the reliability coefficient ranging between 0.61 to 0.89 .

\subsection{Study Variables and Dependent Variable}

Pharmaceutical detailing is defined as “...a marketing approach [which] refers to face-to-face promotional activities directed toward physicians and pharmacy directors. Pharmaceutical representatives typically visit physicians to pitch their medicines. Detailing also includes taking physicians out for meals and giving them gifts in the form of medical textbooks" (Rockoff, 2012). Pharmaceutical sales representatives (in Jordan known as medical representatives) are salespeople employed by pharmaceutical companies to persuade physicians to prescribe their medicines to patients (Fugh-Berman \& Ahari, 2007). Medical representatives are also known as detailers as they offer information on generic and current modes of therapy, the appropriate medicine usage, indications, contraindications, and side effects. Good representatives tailor promotional messages all the time according to the customers' reaction. Physicians with a friendly personality make the representative's task an easy one, because establishing friendly relations is used frequently by representatives to gain favors in the form of extra prescriptions. Some physicians understand this relationship as a 'benefits exchange' so they deal with this situation in a business-like manner, while others require more detailed information so representatives always supply them with print-outs from the company's medical literature in an attempt to persuade them. Sometimes 
when medical representatives fail to reach the physicians, they use their staff as a proxy to transmit their messages to the physicians (Fugh-Berman \& Ahari, 2007).

In addition to information about medicine usage and positioning, detailers give retail price information and dispense free samples. Physicians are expected to benefit from spending time with sales representatives because the information they receive ultimately leads to higher patient recovery rates, enhancing the physicians' reputation in terms of competence and expertise (Gönül, Carter \& Wind, 2000). According to the FDA Prescription Drug Marketing Act (1988), the term 'free sample' (drug sample) means 'a unit of a drug, which is not intended to be sold and is intended to promote the sale of the drug'. Medical representatives' visits to physicians usually include the offering of free medical samples which physicians give to the patients so that they can personally observe the effect of the medicine. This helps them make a decision as to whether to prescribe this particular medicine. Also, physicians' offering free samples to patients is considered as a demonstration of tangible care and something extra which improves the relationship between physician and patient (Gönül et al., 2000).

Rogers (1995) defined 'adoption' (diffusion) as “ ...the process by which a new idea or new product is accepted by a society". The American Marketing Association (2010) defined adoption as "...a process that individuals and firms, in this specific case, physicians, go through when accepting new products". According to Rogers, the adoption process is carried out through five stages, namely knowledge, persuasion, decision, implementation, and confirmation (Rogers, 1983). Pharmaceutical promotions support the customers in all these stages to assure that the customer keep adopting the promoted medicine items. Physician prescribing behavior is a vast broad and complex concept, which includes several dimensions. This study investigated just one dimension, namely medicine adoption because it is the main target of the promotional activities of pharmaceutical companies.

\section{Analysis Results and Hypotheses Test}

According to the purpose of the research and the research framework presented in the previous sections, this section describes the results of the statistical analysis of the data collected according to the research questions and research hypotheses. Both the mean and multicollinearity tests are described in this section.

Descriptive analysis indicated that there is a strong tendency towards pharmaceutical promotion tools (medical representative detailing visits, promotional medicine prices, external medical conference sponsorships and free samples) according to the mean and standard deviation depicted in Table 2.

Table 2. Mean summary for independent variables

\begin{tabular}{lc}
\hline \multicolumn{1}{c}{ Independent Variable } & Mean \\
\hline Medical representative detailing visit & 3.17 \\
Promotional medicine price & 3.8 \\
External medical conference sponsorship & 4.21 \\
Free sampling & 3.97 \\
\hline
\end{tabular}

Results shown in Table 2 represent a high range of acceptance for pharmaceutical promotion tools from the physicians' side. This finding confirmed the notion that the pharmaceutical promotion tools which target physicians are the most widely used as part of the pharmaceutical promotional mix. From the findings it is clear that the highest degree of acceptance was for external medical conference sponsorships with a mean of 4.21. As Taneja (2008) revealed, respondents have perceived sponsorships to be the most important factor (set of promotional tools), followed by free sample expenses with a mean of 3.97. This finding is in agreement with the views of Ma, Stafford, Cockburn and Finkelstein (2003) who emphasized that the pharmaceutical industry spent over $\$ 12$ billion in 1998 to promote its products in the United States. Of this promotional budget, over half was dedicated to supplying physicians with free sample medications for distribution to patients. This expense increased to almost $\$ 15.7$ billion in 2000 , with free sample medications once more topping the budget, having increased by an average of $12.8 \%$ annually since 1996 .

Moreover, multicollinearity is considered as a statistical phenomenon in the multiple regression analysis, which emerges in the presence of a high level of correlation between two or more independent variables. Both tolerance and the variance inflation factor (VIF) are considered as the most frequently used measures to assess multicollinearity (Al Kurdi, 2016; Alshurideh, 2010). Tolerance means the variance proportion in the 
independent variable that is not explained by its relationships with other independent variables Hair and Babin (2003) state that the minimum accepted value of tolerance equals 0.10 , thus a tolerance value less than 0.10 must be inspected. VIF assesses how much of the regression coefficients variance is inflated by multicollinearity problems. There are two criteria to assess that value: a more relaxed criterion in terms of which it is desirable that (VIF) values be lower than 10 and a more conservative one in which it is favorable if (VIF) values are lower than 5 (Hair, Black and Babin, 1987; Kline, 1998). This study depends on the more conservative criterion (less than 5). The multicollinearity test of the four types of pharmaceutical promotion tools was accomplished and all (VIF) values were less than (5). This means there is no collinearity within the collected data, and it reinforces the model by avoiding the problem of having interchangeable beta values between independent variables and then there was no bias.

\section{Findings and Discussion}

\subsection{Measurement Model Analysis}

The partial least square (PLS) method was implemented for data analysis in this study. One of the structural equation modeling (SEM) methods used to evaluate the relationship within a model is the PLS (Hair et al., 2016). Researchers prefer it because of its potential to investigate the small sample sizes (Wang \& Yang, 2016). If it has a prediction objective, it also could reveal good performance. The model is difficult to understand, and the trend is either new or fluctuating (Chin \& Newsted, 1999). The SmartPLS application has been used with its existing features and simple navigation. Normally, two steps are involved in the PLS analysis: measurement model analysis and structural model analysis (Anderson \& Gerbing, 1988). To examine the validity and reliability of the latent variables, the confirmatory factor analysis (CFA) would be implemented by the first measurement (Riskinanto et al., 2017). However, the hypotheses would be tested by the second measurement and it is done by examining path coefficients along with their significance. A confirmatory assessment of reliability, discriminant validity and convergent validity are provided by the analysis for measurement model (Hair et al., 1987). Investigating the value of the loading factor of the model's variables is the first step to measuring the model. We can also achieve this by executing the PLS algorithm function in SmartPLS. Table 3 describes the results of the outer model test.

Table 3 is clearly illustrative of the fact that the Cronbach's alpha values span from 0.717 to 0.871 (for External Medical Conference Sponsorship and for Physicians' Medicine Adoption respectively). According to Gefen et al. (2000) and Nunnally and Bernstein (1978), the lowest value of 0.7 has been satisfied by all the values. By investigating the factor loadings of all variables with their respective constructs, the individual item reliability has also been assessed. As per the outcomes, all variables range from 0.712 to 0.919 (for PRO_MED_1 and for PRO_MED_4 respectively), which have fulfilled the minimal value of 0.7 (Chin, 1998). The composite reliability was checked for final measurement of our model's reliability. According to the findings, the requirement of 0.7 was met by all constructs (Chin, 1998). Hence, the reliability of our research model was concluded as suitable. The convergent validity is another measurement that needs to be considered, which describes the degree of agreement to measure the same concept (Fornell \& Larcker, 1981). In this study, the average variance extracted (AVE) values can be studied to evaluate the convergent validity. Table 3 reveals that for all the constructs the AVE was greater than 0.5, which fulfilled the requirement (Chin, 1998). This depicts a good convergent validity for the scales. With respect to the final measurement of our research model, the discriminant validity was evaluated. By measuring the variance shared between the construct and other constructs, we can also achieve the above point (Fornell \& Larcker, 1981). Table 3 demonstrates the result of the computation. Table 3 reveals that the AVE and all of their square roots were greater than their equivalent coefficients of correlation with other factors. We can say that the discriminant validity test is met by all the constructs (Chin, 1998). Finally, it has been learnt from the findings that both convergent and discriminant validity have been met by our investigations.

Table 3. Convergent validity results which assures acceptable values (Factor loading, Cronbach's Alpha, composite reliability $\geq 0.70 \&$ AVE $>0.5$ )

\begin{tabular}{llcccc}
\hline Constructs & \multicolumn{1}{c}{ Items } & $\begin{array}{c}\text { Factor } \\
\text { Loading }\end{array}$ & $\begin{array}{c}\text { Cronbach's } \\
\text { Alpha }\end{array}$ & CR & AVE \\
\hline ExternalMedical & EXT_MED_1 & 0.839 & 0.717 & 0.726 & 0.617 \\
Conference & EXT_MED_2 & 0.765 & & \\
Sponsorship & EXT_MED_3 & 0.774 & & & \\
& &
\end{tabular}




\begin{tabular}{|c|c|c|c|c|c|}
\hline & EXT_MED_4 & 0.782 & & & \\
\hline \multirow[t]{4}{*}{ Free Sampling } & FREE_SAMP_1 & 0.755 & 0.778 & 0.765 & 0.701 \\
\hline & FREE_SAMP_2 & 0.788 & & & \\
\hline & FREE_SAMP_3 & 0.751 & & & \\
\hline & FREE SAMP 4 & 0.749 & & & \\
\hline \multirow{4}{*}{$\begin{array}{l}\text { Physician's Medicine } \\
\text { Adoption }\end{array}$} & PHY_ADOP_1 & 0.832 & 0.871 & 0.753 & 0.672 \\
\hline & PHY_ADOP_2 & 0.873 & & & \\
\hline & PHY_ADOP_3 & 0.757 & & & \\
\hline & PHY_ADOP_4 & 0.763 & & & \\
\hline \multirow{4}{*}{$\begin{array}{l}\text { Representative Medical } \\
\text { detailing visit }\end{array}$} & REP_MED_1 & 0.797 & 0.771 & 0.712 & 0.677 \\
\hline & REP_MED_2 & 0.794 & & & \\
\hline & REP_MED_3 & 0.798 & & & \\
\hline & REP_MED_4 & 0.779 & & & \\
\hline \multirow{4}{*}{$\begin{array}{l}\text { Promotional Medicine } \\
\text { Price }\end{array}$} & PRO_MED_1 & 0.712 & 0.849 & 0.853 & 0.751 \\
\hline & PRO_MED_2 & 0.773 & & & \\
\hline & PRO_MED_3 & 0.797 & & & \\
\hline & PRO_MED 4 & 0.877 & & & \\
\hline
\end{tabular}

The coefficient of determination ( $\mathrm{R}^{2}$ value) measure is the basis of analyzing the structural model. By squaring the correlation amongst a particular endogenous construct's actual and predicted values (Lin et al., 2010), this coefficient proves to be an effective means of assessing the predictive accuracy of this model (Lin et al., 2014). The coefficient signifies the exogenous latent variables' combined effect on an endogenous latent variable. Since the coefficient represents the squared correlation amongst the predicted and actual values of the variables, it is therefore a valid representation of the extent of variance of the endogenous constructs shielded by either of the exogenous constructs related to it. These values are designated high and weak according to the scope in which they fall, as per Chin (1998). All values falling within the range of 0.33 and 0.67 are direct and the values more than 0.67 are high. The qualities falling within the scope of 0.19 to 0.33 are referred to as weak (Liu et al., 2005). Additionally, estimations below 0.19 are deemed inadmissible. The high predictive power of the model holding approximately $69.1 \%$ is illustrated in Table 4 and Figure 2.

Table 4. $\mathrm{R}^{2}$ of the endogenous latent variables

\begin{tabular}{ccc}
\hline Constructs & $\mathrm{R}^{2}$ & Results \\
\hline Physician's Medicine Adoption & 0.691 & High \\
\hline
\end{tabular}

\subsection{Structural Model Analysis}

Evaluating the structural model is believed to be the second step in using the PLS method (Salloum, Al-Emran, Shaalan \& Tarhini, 2018; Salloum \& Shaalan, 2018; Salloum \& Shaalan, 2018a). According to the analysis of standardized paths, this step provides analyses on constructs' relationships and hypotheses. Table 5 displays the findings of our assessment. Almost 69\% of the variations in Physician's Medicine Adoption is explained and reported by our research model. To verify all the specified hypotheses, researchers have performed a path analysis. The association between the theoretical constructs for the structural model was assessed with the help of an efficient structural equation model utilizing SEM-PLS which derives accurate values of these proposed hypotheses (Al-Emran \& Salloum, 2017; Salloum, Al-Emran \& Shaalan, 2018; Salloum \& Shaalan, 2018b). Table 5 shows these results. It can be seen that all four hypotheses are found to be significant. Based on the data analysis, hypotheses $\mathrm{H} 1, \mathrm{H} 2, \mathrm{H} 2$, and $\mathrm{H} 4$ were supported by the empirical data. The results showed that Representative Medical Detailing Visit significantly influenced Physicians' Medicine Adoption $(\beta=0.131$, $\mathrm{P}<0.001$ ), thereby supporting hypothesis H1. Promotional Medicine Price was determined to be significant in affecting Physicians' Medicine Adoption $(\beta=0.423, \mathrm{P}<0.001$ ), thereby supporting hypotheses H2. Furthermore, External Medical Conference Sponsorship and Free Sampling were found to be significantly influenced by 
Physicians' Medicine Adoption: $(\beta=0.132, \mathrm{P}<0.001)$ and $(\beta=0.182, \mathrm{P}<0.001$, supporting hypotheses $\mathrm{H} 3$ and $\mathrm{H} 4$ respectively. A summary of the hypotheses testing results is shown in Table 5.

Table 5. Results of structural model-research hypotheses significant at $\left.\mathrm{p}^{* *}=<0.01, \mathrm{p}^{*}<0.05\right)$

\begin{tabular}{lllllll}
\hline $\mathrm{H}$ & Relationship & Path & $t$-value & $p$-value & irection & Decision \\
\hline H1 & $\begin{array}{l}\text { Representative Medical detailing } \\
\text { visit->Physician's Medicine Adoption }\end{array}$ & 0.131 & 10.057 & 0.000 & Positive & Supported** \\
H2 & $\begin{array}{l}\text { Promotional Medicine Price->Physician's } \\
\text { Medicine Adoption }\end{array}$ & 0.423 & 6.701 & 0.000 & Positive & Supported** \\
H3 & $\begin{array}{l}\text { External Medical Conference Sponsorship } \\
\text {->Physician's Medicine Adoption }\end{array}$ & 0.132 & 11.021 & 0.000 & Positive & Supported** \\
H4 & $\begin{array}{l}\text { Free Sampling->Physician's Medicine } \\
\text { Adoption }\end{array}$ & 0.182 & 3.482 & 0.001 & Positive & Supported** \\
\hline
\end{tabular}

\section{Recommendations and Implications}

Based on the results of the current research, the following recommendations would help enhance the pharmaceutical companies' promotional efforts directed to the physicians. The correlation between the effect of pharmaceutical promotion tools on physicians' adoption of medicine prescribing in Jordan was reasonably and positively high, so pharmaceutical companies in Jordan are recommended to pay more attention to these promotional tools in their promotional mix in order to better effect physicians' adoption of medicine in their favor.

Among the four types of pharmaceutical promotional tools, Promotional Medicine Price has the greatest effect on Physicians' Adoption since it has the greatest beta value (beta $=0.423$ ). So it is clear that pharmaceutical companies must revise their prices favorably in terms of competitors and the financial ability of patients. Free sampling came in second with a positive effect (Beta $=0.182$ ), Accordingly, pharmaceutical companies are recommended to focus more on free samples, especially offering free trial samples for the patient which in return increases both medicine awareness and sales. Pharmaceutical companies are recommended to increase their focus on creating more innovative promotional activities which combine both medical detailing and free samples.

Both external medical conference sponsorship and the effect of representative medical detailing visits on physicians' adoption were lower that the two mentioned above, with beta values of 0.132 and 0.131 respectively, but it is nevertheless a positive relationship. Therefore, pharmaceutical companies are recommended to attempt to minimize their expenses on external medical conference sponsorships because the results of this study indicate that this tool has the lowest effect on physicians' adoption. Also, pharmaceutical companies are recommended to be aware of the actions and activities of their competitors and do their best in order to increase consumers' awareness as well as increasing their sales by effecting physicians' adoption through hiring well educated and good detailer medical representatives (Alshurideh et al., 2014). Additional research is needed that will take the results of this study to the next level. That is needed to determine whether the correlation between pharmaceutical promotional tools could extend further to other promotional activities such as pharmaceutical advertising and conducting scientific group meetings or whether it could be linked with other marketing mix elements such as digital distribution. Additional research is recommended to be conducted in the future to investigate the opinion of medical representatives about the effect of promotional tools on physicians' perception and adoption.

\section{References}

Al-Emran, M., \& Salloum, S.A. (2017). Students' attitudes towards the use of mobile technologies in e-evaluation. International Journal of Interactive Mobile Technologies (IJIM), 11(5), 195-202.

Al-Dmour, H., \& Al-Shraideh, M. T. (2008). The influence of the promotional mix elements on Jordanian consumer's decisions in cell phone service usage: An analytical study. Jordan Journal of Business Administration, 4(4), 375-392.

Al-Duhaish, A., Alshurideh, M., \& Al-Zu'bi, Z. (2014). The impact of the basic reference group usage on the purchasing decision of clothes (A field study of Saudi youth in Riyadh city). Dirasat: Administrative, 41(2), 205-221. 
Al-dweeri, R. M., Obeidat, Z. M., Al-dwiry, M. A., Alshurideh, M. T., \& Alhorani, A. M. (2017). The impact of e-service quality and e-loyalty on online shopping: moderating effect of e-satisfaction and e-trust. International Journal of Marketing Studies, 9(2), 92-103.

Alkalha, Z., Al-Zu'bi, Z., Al-Dmour, H., \& Alshurideh, M. (2012). Investigating the effects of human resource policies on organizational performance: An empirical study on commercial banks operating in Jordan. European Journal of Economics, Finance and Administrative Sciences, 51(1), 44-64.

AL Kurdi, B. (2016). Healthy-food choice and purchasing behaviour analysis: An exploratory study of families in the UK. Durham University.

Al Kurdi, B. (2017). Investigating the factors influencing parent toy purchase decisions: Reasoning and consequences. International Business Research, 10(4), 104-116.

ALshurideh, M. (2010). Customer service retention-A behavioural perspective of the UK mobile market. Durham University.

Alshurideh, M. (2014). The factors predicting students' satisfaction with universities' healthcare clinics' services: A case-study from the Jordanian higher education sector. Dirasat: Administrative Sciences, 41(2), 451-464.

Alshurideh, M. T. (2016). Exploring the main factors affecting consumer choice of mobile phone service provider contracts. International Journal of Communications, Network and System Sciences, 9(12), 563-581.

Alshurideh, M. T. (2017). A theoretical perspective of contract and contractual customer-supplier relationship in the mobile phone service sector. International Journal of Business and Management, 12(7), 201-210.

Alshurideh, M., Al Kurdi, B. H., Vij, A., Obiedat, Z., \& Naser, A. (2016). Marketing ethics and relationship marketing-An empirical study that measure the effect of ethics practices application on maintaining relationships with customers. International Business Research, 9(9), 78-90.

Alshurideh, M., Bataineh, A., Alkurdi, B., \& Alasmr, N. (2015). Factors affect mobile phone brand choices-Studying the case of Jordan universities students. International Business Research, 8(3), 141-155.

Alshurideh, M., Masa'deh, R., \& Alkurdi, B. (2012). The effect of customer satisfaction upon customer retention in the Jordanian mobile market: An empirical investigation. European Journal of Economics, Finance and Administrative Sciences, 47, 69-78.

Alshurideh, M., Nicholson, M., \& Xiao, S. (2012). The effect of previous experience on mobile subscribers' repeat purchase behaviour. European Journal of Social Sciences, 30(3), 366-376.

Alshurideh, M. T., Shaltoni, A. M., \& Hijawi, D. A. (2014). Marketing communications role in shaping consumer awareness of cause-related marketing campaigns. International Journal of Marketing Studies, 6(2), 163-168.

American Heritage Dictionary of the English Language. (2011). Fifth Edition.

Anderson, J. C., \& Gerbing, D. W. (1988). Structural equation modeling in practice: A review and recommended two-step approach. Psychological Bulletin, 103(3), 411.

Bhatt, A. D. (1993). Drug promotion and doctor: a relationship under change? Journal of Postgraduate Medicine, 39(3), 120.

Chin, W. W. (1998). The partial least squares approach to structural equation modeling. Modern Methods for Business Research, 295(2), 295-336.

Chin, W. W., \& Newsted, P. R. (1999). Structural equation modeling analysis with small samples using partial least squares. Statistical Strategies for Small Sample Research, 1(1), 307-341.

DiMasi, J. A., Hansen, R. W., \& Grabowski, H. G. (2003). The price of innovation: new estimates of drug development costs. Journal of Health Economics, 22(2), 151-185.

Fornell, C., \& Larcker, D. F. (1981). Evaluating structural equation models with unobservable variables and measurement error. Journal of Marketing Research, 39-50.

Fugh-Berman, A., \& Ahari, S. (2007). Following the script: How drug reps make friends and influence doctors. PLoS Medicine, 4(4), 150.

Gefen, D., Straub, D., \& Boudreau, M. C. (2000). Structural equation modeling and regression: Guidelines for research practice. Communications of the Association for Information Systems, 4(1), 7. 
Gönül, F. F., Carter, F., Petrova, E., \& Srinivasan, K. (2001). Promotion of prescription drugs and its impact on physicians' choice behavior. Journal of Marketing, 65(3), 79-90.

Gönül, F. F., Carter, F., \& Wind, J. (2000). What kind of patients and physicians value direct-to-consumer advertising of prescription drugs. Health Care Management Science, 3(3), 215-226.

Hair J., Babin B., M. A., \& S. P. (2003). Essentials of business research methods. United States: Wily.

Hair, J. F., Black, B., \& Babin, B. (1987). Multivariate data analysis. New York, NY: Macmillan.

Hair, J. F., Black, W. C., Babin, B. J., Anderson, R. E., \& Tatham, R. L. (1998). Multivariate data analysis. Prentice hall Upper Saddle River, NJ.

Hair Jr, J. F., Hult, G. T. M., Ringle, C., Sarstedt, M., Hair, J. F. F., Hult, G. T. M., ... Sarstedt, M. (2016). A primer on partial least squares structural equation modeling (PLS-SEM). Sage Publications.

Helper, D. D., \& Strand, L. M. (1989). Opportunities and responsibilities in pharmaceutical care. Am.J.Pharm.Educ., 53, 7S-15S.

Kline, R. (1998). Principles and practice of structural equation modeling. New York: The Guilford Press.

Kotler, P. (2000). Marketing management-International millennium edition. Prentice Hall, New Jersey.

Kremer, S. T. M., Bijmolt, T. H. A., Leeflang, P. S. H., \& Wieringa, J. E. (2008). Generalizations on the effectiveness of pharmaceutical promotional expenditures. International Journal of Research in Marketing, 25(4), 234-246.

Lin, S. C., Persada, S. F., \& Nadlifatin, R. (2014). A study of student behavior in accepting the blackboard learning system: A technology acceptance model (TAM) approach. In Computer Supported Cooperative Work in Design (CSCWD), Proceedings of the 2014 IEEE 18th International Conference on (pp. 457-462). IEEE.

Lin, Y. C., Chen, Y. C., \& Yeh, R. C. (2010). Understanding college students' continuing intentions to use multimedia e-learning systems. World Transactions on Engineering and Technology Education, 8(4), 488-493.

Liu, S. H., Liao, H. L., \& Peng, C. J. (2005). Applying the technology acceptance model and flow theory to online e-learning users' acceptance behavior. E-Learning, 4(6).

M Rogers, E. (1983). Diffusion of innovations. The Free Press.

Ma, J., Stafford, R. S., Cockburn, I. M., \& Finkelstein, S. N. (2003). A statistical analysis of the magnitude and composition of drug promotion in the United States in 1998. Clinical Therapeutics, 25(5), 1503-1517.

McCarthy, E. J. (1964). Basic marketing, Richard D. Irwin, Homewood, IL, 181.

Menlo, C. A., \& Henry, J. (2006). Prescription drug trends, kaiser family foundation. National survey of physicians. Available on Line at: Https://Www.Kff.Org/Tag/Prescription-Drugs/?Paged=3\&orderby=relevance.

Miao-Sheng, C., \& Yu-Ti, S. (2008). Pricing of prescription drugs and its impact on physicians' choice behavior. Health Care Management Science, 11(3), 288-295.

Millenson, M. L. (2003). Getting doctors to say yes to drugs: The cost and quality impact of drug company marketing to physicians. mBlueCross BlueShield Association.

Nunnally, J. C., \& Bernstein, I. H. (1978). Psychometric theory.

Nutescu, E. A., Park, H. Y., Walton, S. M., Blackburn, J. C., Finley, J. M., Lewis, R. K., \& Schumock, G. T. (2005). Factors that influence prescribing within a therapeutic drug class. Journal of Evaluation in Clinical Practice, 11(4), 357-365.

Obeidat, B., Sweis, R., Zyod, D., \& Alshurideh, M. (2012). The effect of perceived service quality on customer loyalty in internet service providers in Jordan. Journal of Management Research, 4(4), 224-242.

Pavan, M. P. (2008). A study to measure market potential \& customers buying motives towards Cipla'sAsthalin Inhaler in Buldana district. MBA Project Report, Department of Business Administration \& Research at SSGM College of Engg., Shegaon.

Physicians (Jordan Department of Statistics, Statistical Yearbook, 2009. (2009). Jordan Department of Statistics, (2009) Statistical Yearbook, Amman, Jordan. 
Riskinanto, A., Kelana, B., \& Hilmawan, D. R. (2017). The moderation effect of age on adopting e-payment technology. Procedia Computer Science, 124, 536-543.

Rockoff, J. D. (2012). Drug reps soften their sales pitches. The Wall Street Journal.

Rogers, E. M. (1995). Diffusion of innovations (4th ed). The Free Press. New York.

Rubin, P. H. (2003). The economics and impact of pharmaceutical promotion. Economic Realities in Health Care Policy, 3(1), 6-19.

Rubin, P. H. (2004). Pharmaceutical marketing: Medical and industry biases.

Salloum, S. A., Al-Emran, M., \& Shaalan, K. (2018). The impact of knowledge sharing on information systems: A review. In International Conference on Knowledge Management in Organizations (pp. 94-106). Springer.

Salloum, S. A., Al-Emran, M., Shaalan, K., \& Tarhini, A. (2018). Factors affecting the e-learning acceptance: A case study from UAE. Education and Information Technologies, 1-22.

Salloum, S. A., \& Shaalan, K. (2018). Investigating students' acceptance of e-learning system in higher educational environments in the UAE: Applying the extended technology acceptance model (TAM). The British University in Dubai.

Salloum, S. A., \& Shaalan, K. (2018a). Adoption of e-book for university students. In International Conference on Advanced Intelligent Systems and Informatics (pp. 481-494). Springer.

Salloum, S. A., \& Shaalan, K. (2018b). Factors affecting students' acceptance of e-learning system in higher education using UTAUT and structural equation modeling approaches. In International Conference on Advanced Intelligent Systems and Informatics (pp. 469-480). Springer.

Sheehan, K. B. (2007). Direct-to-consumer (DTC) branded drug web sites risk presentation and implications for public policy. Journal of Advertising, 36(3), 123-135.

Smith, S. M., \& Albaum, G. S. (2010). An introduction to marketing research. In Proceedings of the 14th Conference on Cross Cultural Research in Business Studies, 14.

Smith, M. (1991). Pharmaceutical marketing: Strategy and cases. Sydney: Pharmaceutical Product Press.

Taneja, G. (2008). Impact of pharmaceutical industry promotion mix on doctor's prescribing behaviour. Asia Pacific Business Review, 4(4), 82-95.

(United States Food and Drug, 2003). (2003). Administration center for drug evaluation and research, guidance for industry: Bioavailability and bioequivalence studies for orally administered drug products-general considerations.

U.S. Department of Health and Human Services. (2006).

Wang, M. H., \& Yang, T. Y. (2016). Investigating the success of knowledge management: An empirical study of small-and medium-sized enterprises. Asia Pacific Management Review, 21(2), 79-91.

Windmeijer, F., Douven, E., \& Mot, E. (2004). Pharmaceutical promotion and gp prescription behaviour. CPB Discussion Paper No 30. Available at: SSRN: Https://Ssrn.Com/Abstract $=536563$ or Http://Dx.Doi.Org/10.2139/Ssrn.536563.

Yang, M., Lien, H. M., \& Chou, S. Y. (2014). Is there a physician peer effect? Evidence from new drug prescriptions. Economic Inquiry, 52(1), 116-137.

Zikmund, W. (2003). Business research methods (7th ed.). United States: South Western- Cengage Learning.

\section{Copyrights}

Copyright for this article is retained by the author(s), with first publication rights granted to the journal.

This is an open-access article distributed under the terms and conditions of the Creative Commons Attribution license (http://creativecommons.org/licenses/by/4.0/). 